\title{
Análise da diversidade genética de cornichão com o uso de marcadores microssatélites $^{1}$
}

\author{
Armando Martins dos Santos², Miguel Dall'Agnol ${ }^{2}$, Aline Janke², Fernanda Bortolini², \\ Kátia Graziela Costa Huber²
}

\footnotetext{
${ }^{1}$ Trabalho financiado pelo projeto Lotassa.

2 Departamento de Plantas Forrageiras e Agrometeorologia, Faculdade de Agronomia da Universidade Federal do Rio Grande do Sul. Av. Bento Gonçalves, 7712 - Caixa Postal 15100, 91540-000, Porto Alegre, RS.
}

RESUMO - O objetivo neste trabalho foi analisar a diversidade genética de 14 materiais de Lotus corniculatus L. por meio de marcadores microssatélites. Foram analisados quatro cultivares e uma população de L. corniculatus e seus respectivos genótipos selecionados visando tolerância e sensibilidade ao alumínio. Foram utilizados 17 pares de primers que detectaram 36 alelos nos 17 locos microssatélites, com média de 2,25 alelos por loco. O resultado da análise de agrupamento com base nos índices de similaridade mostrou a formação de três grupos: um englobando germoplasmas e genótipos selecionados para sensibilidade ao alumínio e outros dois formados por genótipos selecionados visando tolerância ao alumínio tóxico. A análise molecular foi eficiente para detectar e quantificar a variabilidade entre os genótipos, acrescentando informações úteis ao programa de melhoramento. O uso de marcadores microssatélites permite a distinção de genótipos oriundos de um programa de seleção visando tolerância à toxidez por alumínio. As seleções realizadas originam genótipos polimórficos em relação às populações originais.

Palavras-chave: alumínio tóxico, cornichão, marcador molecular, variabilidade genética

\section{Lotus corniculatus L. genetic diversity analysis through microsatellite markers}

\begin{abstract}
The aim of this work was to analyze the genetic diversity of 14 Lotus corniculatus L. materials through microsatellite markers. Four cultivars and one population of L. corniculatus and their respective genotypes selected were analyzed aiming aluminium tolerance and sensibility. The 17 markers used detected a total of 36 alleles, with an average of 2.25 alleles per locus. The result of the similarity analyses showed the formation of three groups: one enclosing germplasm and selected genotypes for aluminium sensibility, while the other two groups were formed by selected genotypes for aluminium tolerance. The molecular analysis was efficient in detecting and quantifying the variability among the genotypes, adding useful information to the breeding program. The utilization of microsatellite markers permitted the distinction of genotypes originated from a selection program aiming aluminium tolerance. The performed selections originate polymorphic genotypes in relation to the original populations.
\end{abstract}

Key Words: birdsfoot trefoil, genetic variability, molecular marker, toxic aluminum

\section{Introdução}

Estresses ambientais estão entre os fatores mais limitantes à produção na região do Cone Sul (Blumenthal \& McGraw, 1999). Entre esses fatores, a acidez do solo e a concomitante toxidez por alumínio (Al) se destacam no Brasil e Chile, podendo ser observada ampla variabilidade de plantas forrageiras com relação à capacidade de tolerar condições de alta toxidez por alumínio (Edmeades et al., 1991).

Somente na América tropical, cerca de 850 milhões de hectares apresentam este tipo de problema (Rao et al., 1993). No Brasil, a ocorrência de solos com problemas de toxidez de alumíno é de aproximadamente $60 \%$ da área, considerando-se as terras com potencial para atividade agrícola; o alumínio é o cátion trocável predominante em mais de um terço dos solos com pH inferior a 5,6 (Abreu Júnior, 2003). Em avaliação realizada por Rheinheimer et al. (2001) no estado do Rio Grande do Sul, 45\% das amostras de solos analisadas até o ano 2000 apresentaram pH abaixo de 5,5.

L. corniculatus destaca-se como uma das principais espécies forrageiras utilizadas em áreas marginais, devido principalmente ao seu valor adaptativo (Sokoloff \& Lock, 2005). Grande parte da facilidade de adaptação está 
relacionada à elevada variabilidade genética dessa espécie. É uma espécie considerada polimórfica em função do ambiente para diversas características morfológicas, para constituintes bioquímicos e também moleculares (Beuselinck \& Steiner, 1992; Garcia de Los Santos, 1997; Steiner, 1999).

A seleção e o melhoramento de genótipos para situações de elevada toxidez por alumínio pode promover a melhor utilização de áreas que apresentem esta característica. O uso de técnicas moleculares concomitantes ao programa de melhoramento permite uma melhor elucidação do comportamento genético dos materiais analisados, não estando restrito apenas a características morfológicas e agronômicas.

O conhecimento da distância genética entre diferentes genótipos é muito utilizado nestes programas, pois permite uma eficiente amostragem e utilização dos recursos genéticos (Kongkiatngam et al., 1996). Os SSR são marcadores que possuem expressão co-dominante, somaticamente estáveis, multialélicos e altamente reprodutíveis. Esses marcadores possuem um elevado conteúdo de informação de polimorfismo, sendo ideais para serem utilizados na identificação e discriminação de genótipos (Ferreira \& Grattapaglia, 1998).

Neste sentido, objetivou-se analisar a diversidade genética de 14 materiais de Lotus corniculatus L. com o uso de marcadores microssatélites.

\section{Material e Métodos}

A extração do DNA genômico e a análise molecular foram realizadas no período de 15 de janeiro a 20 de fevereiro de 2009. A caracterização molecular foi realizada nas cultivares Draco (DR), Estanzuela (ES), San Gabriel(SA) e São Gabriel (SG) e na população UFRGS (UF) de L. corniculatus, bem como nos genótipos selecionados por Santos (2009) para tolerância (DR-T2, ES-T2, SA-T2, SG-T2 e UF-T2) e sensibilidade ao Al (DR-S2, ES-S2, SA-S2, SG-S2 e UF-S2), com o auxílio de marcadores microssatélites (SSR).

A extração do DNA foi realizada segundo a metodologia descrita por Ferreira \& Grattapaglia (1998), com modificações. Cada amostra foi constituída pela mistura (bulk) de 20 plântulas de cada população. Logo após a coleta, o material foi depositado em tubos eppendorf de $1,5 \mathrm{~mL}$ e macerado em nitrogênio líquido. Ao material macerado, foi adicionado $650 \mu \mathrm{L}$ de tampão de extração CTAB (2\% de CTAB, 1,4 mol de NaCl, 20 mmol EDTA e $10 \mathrm{mmol}$ de Tris base $\mathrm{pH} 8,0$ ) previamente aquecido a $65^{\circ} \mathrm{C}$, $14 \mu \mathrm{L}$ de $\beta$-mercaptoetanol, $10 \mu \mathrm{L}$ de proteinase $\mathrm{K}$ e $1 \%$ de PVP. O material macerado foi suspenso no tampão de extração com o auxílio do aparelho vortex. As amostras permaneceram em banho-maria a $65^{\circ} \mathrm{C}$ por 30 minutos, sendo levemente agitadas a cada 10 minutos. Após a retirada do banho, as amostras foram resfriadas no agitador por 30 minutos. Logo depois, foram adicionados $650 \mu \mathrm{L}$ de CIA (24 clorofórmio: 1 álcool isoamílico), sendo as amostras agitadas por 30 minutos. A suspensão foi centrifugada por 15 minutos a 13.000 rotações por minuto (rpm). O sobrenadante foi retirado e transferido para um novo eppendorf, sendo adicionado ao mesmo volume de DNA o volume de isopropanol gelado. Os tubos foram invertidos gentilmente a fim de observar a precipitação do DNA. A solução foi mantida a $4^{\circ} \mathrm{C}$ durante uma noite. No dia seguinte, os tubos foram retirados da geladeira e centrifugados a $13.000 \mathrm{rpm}$ por 10 minutos e o sobrenadante foi descartado. Feito isso, foram acrescentados $500 \mu \mathrm{L}$ da solução de lavagem ( $76 \%$ de etanol e $10 \mathrm{mmol} / \mathrm{L}$ de acetato de amônio) por 10 minutos, sendo posteriormente centrifugado por cinco minutos a $13.000 \mathrm{rpm}$. O sobrenadante foi descartado e os tubos foram mantidos invertidos até a secagem do pellet. Os péletes de DNA foram re-suspensos em $100 \mu \mathrm{L}$ de TE $\mathrm{pH}$ 7,4 (10 mmol/L de Tris base $\mathrm{pH}$ 8,0 e $1 \mathrm{mmol} / \mathrm{L}$ de EDTA), sendo as amostras mantidas em banho-maria a $65^{\circ} \mathrm{C}$ por cinco minutos. Após a retirada do banho, o DNA foi reprecipitado com $50 \mu \mathrm{L}$ de 7,5 mol de acetato de amônio e $375 \mu \mathrm{L}$ de etanol absoluto. As amostras foram centrifugadas por 10 minutos a $13.000 \mathrm{rpm}$. O sobrenadante foi descartado e os tubos foram mantidos invertidos até a completa secagem do pellet. Posteriormente o DNA foi ressuspenso em $50 \mu \mathrm{L}$ de TE $\mathrm{pH} 7,4$. Os tubos foram mantidos por 24 horas a $4^{\circ} \mathrm{C}$ e depois armazenados a $-18^{\circ} \mathrm{C}$.

O DNA das amostras foi quantificado através de eletroforese ( $100 \mathrm{~V}$ por uma hora) em gel de agarose $1 \%$ corado com $0,04 \mu \mathrm{L} / \mathrm{mL}$ de brometo de etídio $(10 \mathrm{mg} / \mathrm{mL})$ para visualização das bandas e comparação com os padrões de concentração conhecida (100, 500 e 1000 ng de DNA).

As reações da polimerase em cadeia (PCR) foram realizadas em um volume final de $10 \mu \mathrm{L}$ por reação, compostos por $3 \mu \mathrm{L}$ da solução de trabalho de DNA $(20 \mathrm{ng} / \mu \mathrm{L}), 1 \mu \mathrm{L}$ de tampão PCR 10X, 0,3 $\mu \mathrm{L}$ de $\mathrm{MgCl} 2(50 \mathrm{mmol} / \mathrm{L}), 0,2 \mu \mathrm{L}$ de dNTP mix (mmol/L) contendo $2,5 \mathrm{mmol}$ de cada um dos quatro nucleotídeos, $0,6 \mu \mathrm{L}$ do primer forward $(10 \mathrm{nmol})$, $0,6 \mu \mathrm{L}$ do primer reverse $(10 \mathrm{nmol}), 0,1 \mu \mathrm{L}$ de Taq DNA Polimerase Qiagen ( $5 \mathrm{U} / \mu \mathrm{L})$ e água MiliQ esterilizada para completar o volume. Utilizaram-se 14 primers de microssatélites desenvolvidos para Lotus japonicus (Regel) Larsen e cinco primers de microssatélites desenvolvidos para Trifolium repens L. (Tabela 1). Todos 19 primers foram utilizados nas análises, exceto dois desenvolvidos para T. repens (prs582 e trssraxx31), por não terem produzido bandas evidentes na amplificação dos fragmentos. 
Tabela 1 - Primers de microssatélites utilizados na amplificação de amostras de DNA genômico de Lotus corniculatus

\begin{tabular}{|c|c|c|}
\hline Primer & Sequência $F\left(5^{\prime}-3^{\prime}\right)$ Sequência R $\left(3^{\prime}-5^{\prime}\right)$ & Motivo/classe \\
\hline${ }^{*} \mathrm{TM} 0021$ & $\begin{array}{c}\text { GGTCATCTTTGTGATAGTAAGTAA } \\
\text { CTGTTGTATCAAGCCACAAG }\end{array}$ & $\begin{array}{l}(\mathrm{CT})_{16} \\
\text { PERFEITO }\end{array}$ \\
\hline${ }^{*}$ TM0029 & $\begin{array}{c}\text { CCTATATAACCTTATTCAAATTGG } \\
\text { ACGAAAACAAAACCCTGCTG }\end{array}$ & $\begin{array}{l}(\mathrm{CT})_{15} \\
\text { PERFEITO }\end{array}$ \\
\hline${ }^{*} \mathrm{TM} 0046$ & $\begin{array}{l}\text { ATCTAACCAAAACGTGCTTC } \\
\text { TTCTTGCCCTTTCTCTGTGG }\end{array}$ & $\begin{array}{l}(\mathrm{CT})_{16} \\
\text { PERFEITO }\end{array}$ \\
\hline${ }^{*}$ TM0072 & $\begin{array}{l}\text { TTATGGTGCTGTATGAGTATG } \\
\text { CTTATGAAACTTAAGCCCTG }\end{array}$ & $\begin{array}{l}(\mathrm{ATT})_{9} \\
\text { PERFEITO }\end{array}$ \\
\hline${ }^{*} \mathrm{TM} 0080$ & $\begin{array}{l}\text { AACAAAATACTAAACTATAGCAAAG } \\
\text { CGTCCCACAАСTCTCTTTAC }\end{array}$ & $\begin{array}{l}(\mathrm{AT})_{14} \\
\text { PERFEITO }\end{array}$ \\
\hline${ }^{*} \mathrm{TM} 0133$ & $\begin{array}{c}\text { CTTTGAAATAACTCATCAAAC } \\
\text { TACTGACACATTCCCCTTGC }\end{array}$ & $\begin{array}{l}(\mathrm{CT})_{24} \\
\text { PERFEITO }\end{array}$ \\
\hline${ }^{*} \mathrm{TM} 0151$ & $\begin{array}{l}\text { CTATCTAATCAAATATGGTGGC } \\
\text { ACGCTTAAACTTGTAAAGGC }\end{array}$ & $\begin{array}{l}(\mathrm{AT})_{25} \\
\text { PERFEITO }\end{array}$ \\
\hline${ }^{*} \mathrm{TM} 0208$ & $\begin{array}{c}\text { TGGCTAGGAATGATGTTGTG } \\
\text { TACAATCATGTTTATAAATGTGG }\end{array}$ & $\begin{array}{l}(\text { AAT })_{15} \\
\text { PERFEITO }\end{array}$ \\
\hline${ }^{*} \mathrm{TM} 0212$ & $\begin{array}{l}\text { CTTCCTTCСTCACCACTTAG } \\
\text { TAAACGAAAATGAAGCAGAG }\end{array}$ & $\begin{array}{l}(\mathrm{CT})_{13} \\
\text { PERFEITO }\end{array}$ \\
\hline${ }^{*} \mathrm{TM} 0256$ & $\begin{array}{l}\text { GAAATTCTTTCCATTCATTG } \\
\text { AGAGAGATAGGGTTGCTCAC }\end{array}$ & $\begin{array}{l}\left(\mathrm{AAAT}_{7}\right. \\
\text { PERFEITO }\end{array}$ \\
\hline${ }^{*} \mathrm{TM} 0314$ & $\begin{array}{c}\text { TGTGATTAGTGATTAGAAAGTGAG } \\
\text { TTTGACCAAACTTCCTTCAC }\end{array}$ & $\begin{array}{l}(\mathrm{CT})_{14} \\
\text { PERFEITO }\end{array}$ \\
\hline${ }^{*} \mathrm{TM} 0756$ & $\begin{array}{l}\text { GCACCTACCAAATAAACAGC } \\
\text { CTCCCATTGAACGCCTTGAC }\end{array}$ & $\begin{array}{l}(\mathrm{AAG})_{6} \\
\text { PERFEITO }\end{array}$ \\
\hline${ }^{*} \mathrm{TM} 0817$ & $\begin{array}{c}\text { TTGCTCATGTGAGAAAGAAC } \\
\text { GCTTTAAAATGACGTCCTAATC }\end{array}$ & $\begin{array}{l}(\text { AAT })_{19} \\
\text { PERFEITO }\end{array}$ \\
\hline${ }^{*}$ TM 1491 & $\begin{array}{l}\text { TCAAAAGTCTGATTTGGAGG } \\
\text { TTGTAAAGTGAAAGCAATGG }\end{array}$ & $\begin{array}{l}(\mathrm{AAG})_{6} \\
\text { PERFEITO }\end{array}$ \\
\hline${ }^{* *}$ ats 070 & $\begin{array}{l}\text { GTCATTGGTGATGGTGTTCT } \\
\text { TTTCGTCAGTGGCGGTGCTC }\end{array}$ & $\begin{array}{l}(\mathrm{CA})_{\mathrm{n}} \\
\text { PERFEITO }\end{array}$ \\
\hline **ats 226 & $\begin{array}{l}\text { CATCTACTCACCACCACCTA } \\
\text { CAGCAGCAGCAGCAGCGATA }\end{array}$ & $\begin{array}{l}(\mathrm{ATG})_{\mathrm{n}} \\
\text { PERFEITO }\end{array}$ \\
\hline${ }^{* *} \operatorname{prs} 582$ & $\begin{array}{c}\text { CCGGTTCGATTCAACAAGTT } \\
\text { CTGCAGATCCAGTAATGATTTCC }\end{array}$ & $\begin{array}{l}(\text { TTC })_{\mathrm{n}} \\
\text { PERFEITO }\end{array}$ \\
\hline${ }^{* *}$ prs 612 & $\begin{array}{l}\text { TTGAACTAGTCGTTGGATGGG } \\
\text { GAGAGGGTTTCAGGAACATACG }\end{array}$ & $\begin{array}{l}(\text { ATG })_{n} \\
\text { PERFEITO }\end{array}$ \\
\hline${ }^{* *}$ TRSSRAXX31 & $\begin{array}{c}\text { TCTGTTTTGTTGGCCATGC } \\
\text { TTGCAAAGTGTTTGGAAGGA }\end{array}$ & $\begin{array}{l}(\mathrm{GT})_{7} \\
\text { PERFEITO }\end{array}$ \\
\hline
\end{tabular}

* Primer desenvolvido para Lotus japonicus (Regel) Larsen; ** Primer desenvolvido para Trifolium repens L.

As condições de amplificação de SSR foram realizadas conforme Bortolini (2008), com modificações, as quais consistiam de uma desnaturação inicial de $94^{\circ} \mathrm{C}$ por 5 minutos, seguidos por sete ciclos de 1 minuto a $94^{\circ} \mathrm{C}, 1$ minuto a $61^{\circ} \mathrm{C}, 1$ minuto a $72^{\circ} \mathrm{C}$, com uma redução na temperatura de anelamento de $1^{\circ} \mathrm{C}$ por ciclo, seguido de 25 ciclos de 1 minuto a $94^{\circ} \mathrm{C}, 1$ minuto a $55^{\circ} \mathrm{C}$ e 1 minuto a $72^{\circ} \mathrm{C}$ e, seis ciclos de 45 segundos a $94^{\circ} \mathrm{C}, 45$ segundos a $54^{\circ} \mathrm{C}$ e 45 segundos a $72^{\circ} \mathrm{C}$, e por fim, extensão a $72^{\circ} \mathrm{C}$ por 8 minutos e estoque a $7^{\circ} \mathrm{C}$.

Após a amplificação, foram acrescentados $4 \mu \mathrm{L}$ de tampão de amostra $(4 \mathrm{~g} / \mathrm{mL}$ de sacarose, $2,5 \mathrm{mg} / \mathrm{mL}$ de azul de bromofenol e TE $\mathrm{pH} 7,4$ ) em cada amostra, sendo os fragmentos amplificados foram visualizados em gel de agarose de alta resolução (Agarose 1000) 4\% corado com $0,08 \mu \mathrm{L} / \mathrm{mL}$ de brometo de etídio ( $10 \mathrm{mg} / \mathrm{mL})$, submerso em tampão TBE $1 \mathrm{X}$, a uma corrente de $100 \mathrm{~V}$ por duas horas.
Após a eletroforese, o gel era visualizado em um transiluminador de luz ultravioleta (comprimento de onda de $260 \mathrm{~nm}$ ) e fotografado, para que os fragmentos das amostras fossem determinados por comparação a um padrão de 100 pares de bases (pb), pelo programa Kodak EDAS 290 (Electrophoresis Documentation and Analysis System). Foi construída uma matriz binária dos dados atribuindo-se o valor 1 para a presença e zero para a ausência de bandas. A partir dessa matriz, com o auxílio do programa Numerical Taxonomy and Multivariate Analysis System NTSYSpc, versão 2.1 (Rohlf, 2000) e utilizando o coeficiente de Jaccard, foi gerada uma matriz de similaridade para comparação de todos os genótipos.

A análise de agrupamento foi realizada a partir dos coeficientes de similaridade entre os genótipos, utilizando-se, como critério de agrupamento, o método baseado na média das distâncias (UPGMA, Unweighted Pair-Group Method 
Using an Arithmetic Average) com o auxílio do programa NTSYS. Foram calculados o número total de alelos por loco (A), e as frequências genotípicas e alélicas.

\section{Resultados e Discussão}

Os 17 marcadores analisados detectaram um total de 36 alelos nas quatro cultivares (populações Draco, Estanzuela, San Gabriel e São Gabriel), na população UFRGS e nos nove genótipos contrastantes (DR-S2, ES-S2, SA-S2, SG-S2, UF-S2, DR-T2, ES-T2, SG-T2 e UF-T2) de L. corniculatus avaliados. O número de alelos por loco variou de 1 (TM0029, TM0133, TM0151, TM0212, TM0256 e TM1491) a 5 (ATS070, ATS226 e PRS612), com média de 2,25 alelos por loco. Os tamanhos alélicos variaram de 60 a 530 pares de bases (pb) (Tabela 2). Todos os locos foram capazes de detectar pelo menos um alelo em cada um dos genótipos de cornichão analisados.

Todo o material analisado era tetraplóide $(2 n=4 x=24)$ O padrão de bandas gerado pelos primers para microssatélites não possibilitou a análise da heterozigose em função da geração de bandas inespecíficas.

Sardaro et al. (2008), analisando 11 populações selvagens de cornichão, com o auxílio de cinco marcadores SSR, detectaram a presença, em média, de 13,6 alelos por loco. A grande variação observada entre o número de alelos existentes em populações selvagens e cultivares deve-se principalmente à estreita base genética utilizada em programas de melhoramento (Tanksley \& McCouch, 1997).

A partir da matriz de similaridade genética (Tabela 3), obtida pelo índice de Jaccard, foi gerado um dendrograma (Figura 1), o qual apresentou um coeficiente de correlação cofenético elevado $(\mathrm{r}=0,78)$, indicando a representatividade do mesmo em relação à matriz de similaridade genética. A similaridade média entre os genótipos foi de 0,60 , variando de 0,40 a 0,81 . A utilização da similaridade média como ponto de corte permitiu a formação de três grupos.

O primeiro grupo formado envolve o maior número de materiais, sendo composto por três cultivares (DR, ES e SG), pela população UF e pelos cinco genótipos selecionados para sensibilidade ao alumínio. O segundo grupo foi formado pela cv. San Gabriel e pelos genótipos ES-T e DR-T. Oúltimo grupo foi formado por apenas dois genótipos selecionados para tolerância ao alumínio (UF-T2 e SG-T2).

Essa organização permite concluir que, em nível molecular, não houve diferenciação entre genótipos selecionados para sensibilidade e germoplasmas originais, exceto para a cv. San Gabriel, que se enquadrou num grupo à parte dos demais.

Tabela 2 - Tamanho alélico e número de alelos de 17 marcadores microssatélites utilizados na caracterização germoplasmas de cornichão

\begin{tabular}{|c|c|c|}
\hline Primer & Tamanho alélico (PB) & Número de alelos (A) \\
\hline *TM0021 & $160-430$ & 2 \\
\hline${ }^{*}$ TM0029 & 135 & 1 \\
\hline${ }^{*} \mathrm{TM} 0046$ & $160-410$ & 3 \\
\hline${ }^{*}$ TM0072 & $125-160$ & 2 \\
\hline${ }^{*} \mathrm{TM} 0080$ & $127-241$ & 2 \\
\hline${ }^{*} \mathrm{TM} 0133$ & 168 & 1 \\
\hline${ }^{*} \mathrm{TM} 0151$ & 165 & 1 \\
\hline${ }^{*}$ TM0208 & $60-115$ & 3 \\
\hline${ }^{*} \mathrm{TM} 0212$ & 143 & 1 \\
\hline${ }^{*}$ TM0256 & 135 & 1 \\
\hline${ }^{*}$ TM0314 & 149 & 1 \\
\hline${ }^{*} \mathrm{TM} 0756$ & 164 & 1 \\
\hline${ }^{*}$ TM0 017 & $127-167$ & 1 \\
\hline${ }^{*}$ TM 1491 & 149 & 1 \\
\hline${ }^{* *}$ ATS 070 & $105-530$ & 5 \\
\hline${ }^{* *}$ A TS 226 & $130-370$ & 5 \\
\hline${ }^{* *}$ PRS 612 & $132-350$ & 5 \\
\hline Total & & 36 \\
\hline Média & & 2,25 \\
\hline Min - Max & $60-530$ & $1-5$ \\
\hline
\end{tabular}

Tabela 3 - Matriz de similaridade genética de germoplasmas de Lotus corniculatus analisados pela técnica de microssatélites

\begin{tabular}{|c|c|c|c|c|c|c|c|c|c|c|c|c|c|c|}
\hline & DRACO & SÃOGAB & SA-S2 & ESTANZ & UFRGS & DR-S2 & SG-S2 & ES-T2 & UF-T2 & DR-T2 & SANGAB & SG-T2 & ES-S2 & $\overline{\text { UF-S2 }}$ \\
\hline DRACO & 1,00 & & & & & & & & & & & & & \\
\hline SÃO GABRIEL & 0,72 & 1,00 & & & & & & & & & & & & \\
\hline SA-S2 & 0,76 & 0,76 & 1,00 & & & & & & & & & & & \\
\hline ESTANZUELA & 0,74 & 0,74 & 0,77 & 1,00 & & & & & & & & & & \\
\hline UFRGS & 0,69 & 0,81 & 0,67 & 0,71 & 1,00 & & & & & & & & & \\
\hline DR-S2 & 0,60 & 0,71 & 0,81 & 0,68 & 0,62 & 1,00 & & & & & & & & \\
\hline SG-S2 & 0,60 & 0,55 & 0,69 & 0,58 & 0,47 & 0,70 & 1,00 & & & & & & & \\
\hline ES-T2 & 0,69 & 0,57 & 0,67 & 0,60 & 0,54 & 0,62 & 0,62 & 1,00 & & & & & & \\
\hline UF-T2 & 0,55 & 0,61 & 0,70 & 0,58 & 0,52 & 0,65 & 0,65 & 0,56 & 1,00 & & & & & \\
\hline DR-T2 & 0,54 & 0,48 & 0,52 & 0,47 & 0,45 & 0,52 & 0,52 & 0,61 & 0,58 & 1,00 & & & & \\
\hline SAN GABRIEL & 0,63 & 0,57 & 0,61 & 0,60 & 0,54 & 0,56 & 0,50 & 0,73 & 0,63 & 0,61 & 1,00 & & & \\
\hline SG-T2 & 0,46 & 0,41 & 0,50 & 0,45 & 0,42 & 0,44 & 0,44 & 0,52 & 0,65 & 0,48 & 0,68 & 1,00 & & \\
\hline ES-S2 & 0,61 & 0,67 & 0,70 & 0,63 & 0,63 & 0,72 & 0,65 & 0,70 & 0,67 & 0,52 & 0,70 & 0,57 & 1,00 & \\
\hline UF-S2 & 0,47 & 0,62 & 0,66 & 0,59 & 0,53 & 0,73 & 0,61 & 0,52 & 0,56 & 0,54 & 0,52 & 0,40 & 0,75 & 1,00 \\
\hline
\end{tabular}




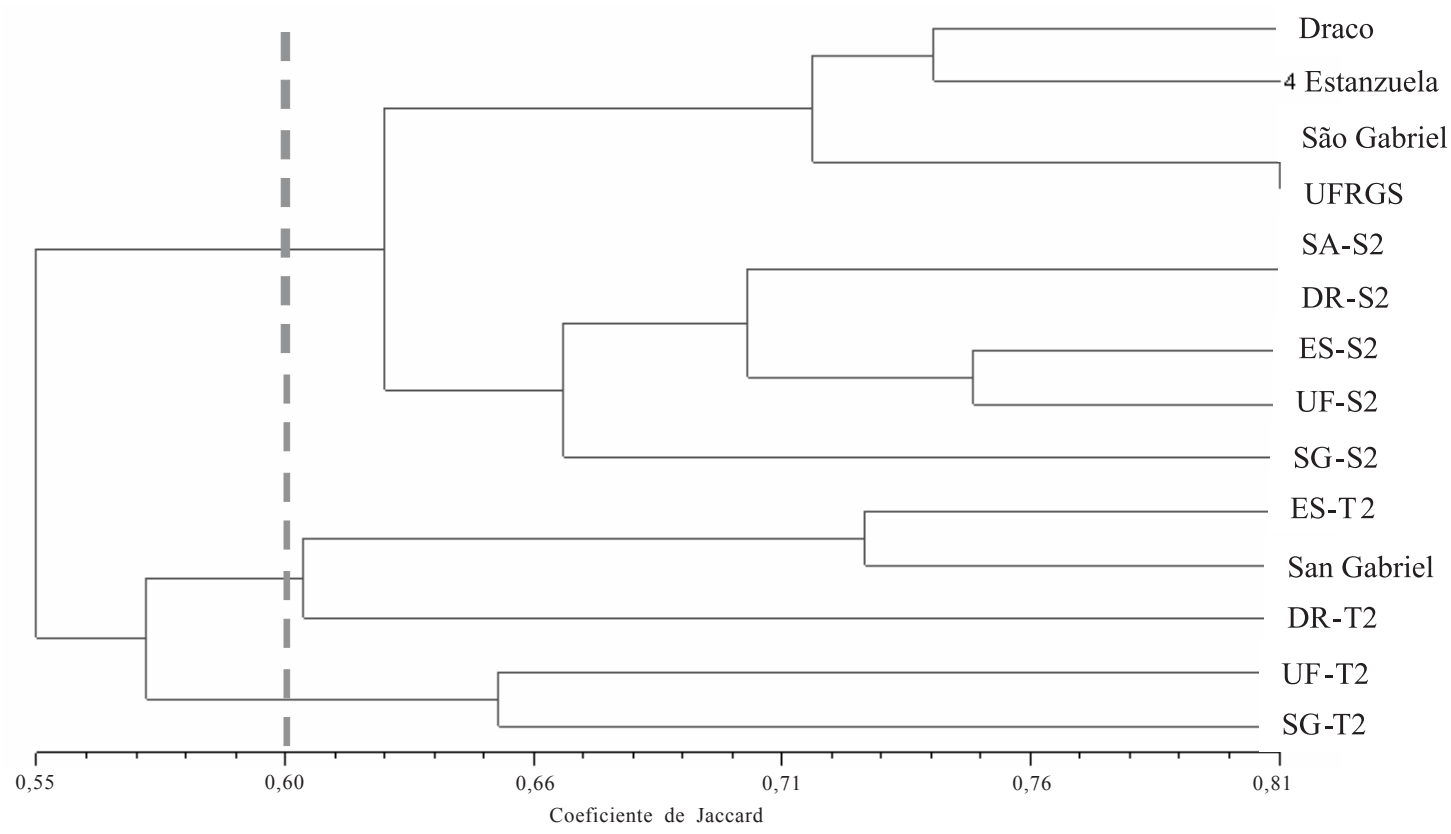

A linha tracejada indica a distância média e o ponto de corte no dendrograma.

Figura 1 - Similaridade genética de germoplasmas de Lotus corniculatus avaliada utilizando-se marcadores microssatélites.

Os genótipos selecionados para tolerância se organizaram separadamente dos demais, com formação de dois grupos. Ao associar esses grupos com os resultados da caracterização agronômica (Santos, 2009), pode-se inferir que o grupo II, formado pela cv. San Gabriel e pelos genótipos ES-T2 e DR-T2, compreende de forma geral materiais que se destacaram em situações de moderada toxidez por alumínio $(25,1 \%)$, enquanto no grupo III, formado por SG-T2 e UF-T2, tem-se genótipos que se destacaram em toxidez mais elevada (41,9\% de Al). A tolerância ao alumínio é uma característica herdável e apresenta diferenças entre as espécies em relação ao seu controle, podendo ser regulada por um ou mais genes dominantes ou por vários genes de efeitos aditivos atuantes em diferentes rotas bioquímicas (Kochian, 1995). Trabalhos realizados em milho apontam valores de herdabilidade para deposição de calose de 0,71 (Eticha et al., 2005), enquanto em alfafa e feijão este valor foi superior a 0,90 (López-Marin et al., 2009; Narasimhamoorthy et al., 2007). A utilização de cultivares capazes de se desenvolverem e se manterem em solos ácidos, com um mínimo necessário de calcário, é uma alternativa ambientalmente e economicamente sustentável. O menor custo com correção da acidez e o maior desenvolvimento radicular manifestado nas plantas tolerantes ao alumínio pode viabilizar a utilização de áreas que apresentem solos ácidos. Entretanto, os materiais selecionados no presente trabalho ainda necessitam de testes sob condições de campo, visando um conhecimento mais aprofundado do comportamento das populações tolerantes em condições reais de utilização.

As espécies de Lotus apresentam grande variabilidade genética, tanto intra quanto interespecífica, que necessita ser melhor compreendida e utilizada em programas de melhoramento, na tentativa de evitar os gargalos genéticos (Steiner, 1999). A elevada similaridade existente entre a maioria dos materiais estudados pode ser o resultado da utilização de uma base genética semelhante no desenvolvimento de novas cultivares, principalmente quando o programa de melhoramento é desenvolvido a partir de cultivares previamente lançadas por seleção massal ou recorrente (Blumenthal \& McGraw, 1999).

O maior índice de similaridade observado em relação aos materiais analisados foi de 0,81 entre a população UFRGS e a cv. São Gabriel e entre os genótipos SA-S2 e DR-S2. Os menores índices foram de 0,40 entre os genótipos SG-T2 e UF-S2 (Figura 1). A maior similaridade encontrada entre a população UFRGS e a cv. São Gabriel pode ter ocorrido em decorrência da primeira ter sido originada a partir de um programa de seleção que utilizou a cv. São Gabriel como germoplasma base (Perez, 2003).

Após terem sofrido dois ciclos de seleção para tolerância ao Al (UF-T2 e SG-T2), ocorreu um distanciamento destes em relação aos germoplasmas de origem. No entanto, mantiveram entre si uma maior similaridade. Apesar disso, foram percebidas alterações discretas na similaridade entre os genótipos após o melhoramento. 
O acompanhamento do número e da frequência alélica dos indivíduos que fazem parte de um programa de melhoramento, pode ser realizado com o auxílio de marcadores moleculares, pela comparação genética com os seus progenitores. Dessa maneira, pode-se determinar se houve alguma alteração na freqüência alélica da população. Através da análise desses dados, o melhorista pode decidir o momento mais adequado para a introdução de novas fontes de variabilidade à população (Brondani et al., 2004).

Os marcadores utilizados neste trabalho foram desenhados para outras espécies e, apesar disso, mostraram-se eficientes na diferenciação dos genótipos de L. corniculatus analisados, corroborando os demais trabalhos que também utilizaram primers heterólogos. Sawasato et al. (2008) analisaram a diversidade genética entre 64 acessos de Paspalum urvillei Steudel utilizando marcadores desenvolvidos para Lolium multiflorum L. e Trifolium repens L. Sardaro et al. (2008) acessaram a variabilidade genética existente entre 11 populações selvagens de $L$. corniculatus com o auxílio de cinco pares de primers desenvolvidos para L. japonicus.

A maior limitação na utilização dos SSR está no elevado custo requerido para o desenvolvimento de primers específicos, quando os mesmos não estão disponíveis para a espécie a ser estudada. Entretanto, nas situações onde ocorre a conservação de sítios de microssatélites entre as espécies relacionadas, a transferência dos marcadores é possível utilizando-se primers heterólogos (Faleiro, 2007).

Diversos trabalhos relacionados ao estudo da diversidade genética em populações naturais já foram realizados com a técnica de microssatélites. Contudo, existem poucos trabalhos referentes a diferenças genéticas entre cultivares ou populações. Em alfafa, Flajoulout et al. (2005) investigaram satisfatoriamente o nível de diferenciação entre sete cultivares originadas de um programa de melhoramento, e entre estas cultivares e o material que lhes originaram, com oito marcadores SSR desenvolvidos para Medicago truncatula. Sete cultivares de Lolium perenne apresentaram diferenças inter e intraespecíficas através de 22 marcadores SSR (Kubik et al., 2001).

O sucesso no desenvolvimento de novas cultivares depende da escolha dos progenitores e do planejamento dos cruzamentos que devem ser realizados ao longo do programa (Borém \& Miranda, 2005). Os marcadores moleculares atuam como uma ferramenta eficiente na análise da variabilidade genética dos potenciais genitores, identificando diferenças entre os materiais em nível de DNA. As técnicas moleculares fornecem aos pesquisadores uma nova fonte de informações, que utilizadas em conjunto com os dados morfológicos e agronômicos acabam contribuindo para o aumento da eficácia do programa (Faleiro, 2007).

\section{Conclusões}

Os marcadores microssatélites são eficientes para detectar e quantificar a variabilidade existente; são capazes de separar os genótipos de cornichão tolerantes ao alumínio. O uso de marcadores microssatélites permite a distinção de genótipos oriundos de um programa de seleção visando tolerância à toxidez por alumínio. As seleções realizadas com esta finalidade originaram genótipos polimórficos, em relação às populações originais.

\section{Referências}

ABREU JÚNIOR, C.H.; MURAOKA, T.; LAVORANTE, A.F. Relações entre acidez e propriedades químicas de solos brasileiros. Scientia Agricola, v.60, n.3, p.543-548, 2003.

BEUSELINCK, P.R.; STEINER, J.J. A proposed framework for identifying, quantifying, and utilizing plant germplasm resources. Field Crops Research, v.29, p.261-272, 1992.

BLUMENTHAL, M.J.; McGRAW, R.L. Lotus adaptation, use and manageament. In: BEUSELINCK, P.R. (Ed.). Trefoil: the science and technology of Lotus. Madison: The American Society of Agronomy, 1999. p.1-20.

BORÉM, A.; MIRANDA, G.V. Melhoramento de plantas. 4.ed Viçosa, MG: Universidade Federal de Viçosa, 2005. 525p.

BORTOLINI, F. Análise da diversidade genética e avaliação de características morfofisiológicas associadas à tolerância à seca em diferentes genótipos de trevo branco (Trifolium repens L.). 2008. 198f. Tese (Doutorado em Zootecnia) Faculdade de Agronomia, Universidade Federal do Rio Grande do Sul, Porto Alegre.

BRONDANI, C.; BRONDANI, R.P.V.; BORBA, T.C.O. et al. Utilização de marcadores microssatélites no melhoramento populacional do arroz. Santo Antônio de Goiás: Embrapa Arroz e Feijão, 2004. 32p. (Documentos, 169).

EDMEADES, D.C.; BLAMEY, F.P.C.; ASHER, C.J. et al. Effects of $\mathrm{pH}$ and aluminium on the growth of temperate pastures espécies. I. Temperate grasses and legumes supplied with inorganic nitrogen. Australian Journal of Agricultural Research, v.42, p.559-569, 1991.

ETICHA, D.; THÉ, C.; WELCKERC, C. et al. Aluminium-induced callose formation in root apices: inheritance and selection trait for adaptation oftropical maize to acid soils. Field Crops Research, v.93, p.252-263, 2005.

FALEIRO, F.G. Marcadores genético-moleculares aplicados a programas de conservação e uso de recursos genéticos. Planaltina: Embrapa Cerrados, 2007. 102p.

FERREIRA, M.E.; GRATTAPAGLIA, D. Introdução ao uso de marcadores moleculares em análise genética. 3.ed. Brasília: Embrapa Cenargem, 1998. 220p.

FLAJOULOT, S.; RONFORT, J.; BAUDOUIN, P. et al. Genetic diversity among alfalfa (Medicago sativa) cultivars coming from a breeding program, using SSR markers. Theoretical and Applied Genetics, v.111, p.1420-1429, 2005.

GARCÍA-DE LOS SANTOS, A.; BROM, S. Characterization of two plasmid-borne lps $\beta$ loci of Rhizobium etli required for 
lipopolysaccharide synthesis and for optimal interaction with plants. Molecular Plant-Microbe Interactions, v.10, n.7, p.891-902, 1997.

KOCHIAN, L.V. Cellular mechanisms of aluminum toxicity and resistance in plants. Annual Review Plant Physiology, v.46, p.237-260, 1995.

KONGKIATNGAM, P.; WATERWAY, M.J.; COULMAN, B.E. et al. Genetic variation among cultivars of red clover (Trifolium pratense L.) detected by RAPD markers amplified from bulk genomic DNA. Euphytica, v.89, p.355-361, 1996.

KUBIK, C.; SAWKINS, M.; MEYER, W.A. et al. Genetic diversity in seven perennial ryegrass (Lolium perenne L.) cultivars based on SSR markers. Crop Science, v.41, p.1565-1572, 2001.

LÓPEZ-MARIN, H.D.; RAO, I.M.; BLAIR, M.W. Quantitative trait loci for root morphology traits under aluminum stress in common bean (Phaseolus vulgaris L.). Theoretical and Applied Genetics, v.119, p.449-458, 2009.

NARASIMHAMOORTHY, B.; BOUTON, J.H.; OLSEN, K.M. et al. Quantitative trait loci and candidate gene mapping of aluminum tolerance in diploid alfalfa. Theoretical and Applied Genetics, v.114, p.901-913, 2007.

PEREZ, N.B. Melhoramento genético de leguminosas de clima temperado - alfafa (Medicago sativa $\mathrm{L}$ ) e cornichão (Lotus corniculatus L.) - para aptidão ao pastejo. 2003. 175f. Tese (Doutorado em Zootecnia) - Faculdade de Agronomia, Universidade Federal do Rio Grande do Sul, Porto Alegre.

RAO, I.M.; ZEIGER, R.S.; VERA, R. et al. Selection and breeding for acid-soil tolerance in crops. Bioscience, v.43, n.7, p.454-465, 1993.
RHEINHEIMER, D.S.; GATIBONI, L.C.; KAMINSKI, J. et al. 2001. Situação da fertilidade dos solos no Estado do Rio Grande do Sul. Santa Maria: Departamento de Solos da UFSM, 2001. 41p. (Boletim Técnico, 2).

ROHLF, F.J. NT-SYS pc. Numerical taxonomy and multivariate analysis system. Version 2.1. New York: Exter Software, 2000.

SARDARO, M.L.S.; ATALLAH, M.; TAKAVOL, E. et al. Diversity for AFLP and SSR in natural populations of Lotus corniculatus L. from Italy. Crop Science, v.48, p.1080-1089, 2008.

SANTOS, A.M. Melhoramento genético de Lotus corniculatus visando tolerância à toxidez por alumínio. 2009. $203 \mathrm{f}$. Tese (Doutorado em Zootecnia) - Programa de Pós-Graduação em Zootecnia, Faculdade de Agronomia, Universidade Federal do Rio Grande do Sul, Porto Alegre.

SAWASATO, J.T.; DALL'AGNOL, M.; CONCEIÇÃO, D.P. et al. Utilização de microssatélites e RAPD na caracterização molecular de acessos de Paspalum urvillei Steudel. Revista Brasileira de Zootecnia, v.37, n.8, p.1366-1374, 2008.

SOKOLOFF, D.D.; LOCK, J.M. Loteae. In: LEWIS, G.; SCHRIRE, B.; MAcKINDER, B.; LOCK, M. (Ed.) Legumes of the world. United Kingdom: BATH Press, 2005. p.455-466.

STEINER, J.J. Birdsfoot trefoil origins asn germoplasm diversity. In: BEUSEULINK, P.R. (Ed.). Trefoil: The science and technology of the Lotus. Madison: The American Society of Agronomy, 1999. p.81-96.

TANKSLEY, S.D.; McCOUCH, S.R. Seed banks and molecular maps: unlocking genetic potential from the wild. Science, v.277, p.1063-1066, 1997. 